\title{
Leu124Serfs*26, a novel AGPAT2 mutation in congenital generalized lipodystrophy with early cardiovascular complications
}

\author{
Renan Magalhães Montenegro Junior ${ }^{1 *} \mathbb{0}$, Grayce Ellen da Cruz Paiva Lima' ${ }^{1}$ Virgínia Oliveira Fernandes ${ }^{1}$, \\ Ana Paula Dias Rangel Montenegro ', Clarisse Mourão Melo Ponte' ', Lívia Vasconcelos Martins', \\ Daniel Pascoalino Pinheiro², Maria Elisabete Amaral de Moraes², Manoel Odorico de Moraes Filho² \\ and Catarina Brasil d'Alva'
}

\begin{abstract}
Background: Congenital generalized lipodystrophy (CGL) is a rare autosomal recessive disorder characterized by the near-total loss of subcutaneous adipose tissue soon after birth, resulting in ectopic fat deposition and severe metabolic disturbances. Most cases are caused by AGPAT2 or BSCL2 gene mutations. We aimed to report two unrelated CGL patients with a novel frameshift mutation in AGPAT2 (p.Leu124Serfs*26).

Methods: Clinical features and laboratory were obtained by medical interview and medical records review. DNA was extracted, amplified and sequenced. Mutation Taster was used to estimate the potential biological impact of the AGPAT2 mutations on the protein function.

Results: Patient 1: a 30-year-old woman with lipodystrophy phenotype at birth and diagnosis of diabetes at age 13 presented with severe hypertriglyceridemia and pancreatitis at age 17, hypertension and albuminuria at age 18, proliferative diabetic retinopathy with visual loss at age 25 , and an acute myocardial infarction due to multivessel coronary disease during a hospitalization for forefoot amputation at age 29. At this time, she required hemodialysis due to endstage renal disease. Patient 2: a 12-year-old girl with lipodystrophy phenotype and hypertriglyceridemia detected in the first year of life and abnormalities in the global longitudinal strain, evaluated by speckle-tracking echocardiography last year. Molecular analysis identified a c.369_372delGCTC (p.Leu124Serfs*26) AGPAT2 mutation in both unrelated patients, a compound heterozygous mutation in Patient 1, and homozygous mutation in Patient 2.

Conclusion: We describe two unrelated patients with type 1 CGL due to Leu124Serfs*26, a novel AGPAT2 frameshift mutation, presenting as early cardiovascular disease. These findings suggest an association between Leu124Serfs*26 and a more aggressive phenotype.
\end{abstract}

Keywords: Congenital generalized lipodystrophy, AGPAT2, Cardiovascular disease

*Correspondence: renanmmji@gmail.com

${ }^{1}$ Brazilian Group for the Study of Inherited and Acquired Lipodystrophies (BRAZLIPO), Faculdade de Medicina, Universidade Federal do Ceará, Rua Professor Costa Mendes, 1608, Rodolfo Teófilo, Fortaleza, Ceará 60416200, Brazil

Full list of author information is available at the end of the article

\section{Background}

Congenital generalized lipodystrophy (CGL; OMIN 608594) is a rare autosomal recessive disorder characterized by the total or near-total loss of subcutaneous adipose tissue soon after birth, resulting in ectopic fat deposition and metabolic complications. These patients present severe insulin resistance (IR), diabetes mellitus,

c) The Author(s) 2020. This article is licensed under a Creative Commons Attribution 4.0 International License, which permits use, sharing, adaptation, distribution and reproduction in any medium or format, as long as you give appropriate credit to the original author(s) and the source, provide a link to the Creative Commons licence, and indicate if changes were made. The images or other third party material in this article are included in the article's Creative Commons licence, unless indicated otherwise in a credit line to the material. If material is not included in the article's Creative Commons licence and your intended use is not permitted by statutory regulation or exceeds the permitted use, you will need to obtain permission directly from the copyright holder. To view a copy of this licence, visit http://creativeco mmons.org/licenses/by/4.0/. The Creative Commons Public Domain Dedication waiver (http://creativecommons.org/publicdomain/ zero/1.0/) applies to the data made available in this article, unless otherwise stated in a credit line to the data. 
hypertriglyceridemia, hepatic steatosis, and cardiovascular disease [1-3].

CGL is classified into four subtypes-1, 2, 3, and 4according to the affected gene, AGPAT2, BSCL2, CAV-1, and CAVIN1, respectively. Most cases (95\%) are subtypes 1 (CGL1) or 2 (CGL2). AGPAT2 is located in chromosome 9q34 and encompasses six exons [4]. This gene codes a homonymous protein (1-acylglycerol-3-phosphate acyltransferase- $\beta$ ) that triggers the synthesis of triglycerides inside the adipocyte, converting lysophosphatidic acid to phosphatidic acid [5, 6]. This mutation influences the peroxisome proliferator-activated receptor gamma (PPAR $\gamma)$, the main regulator of adipocyte differentiation [7-9].

Different AGPAT2 mutations have been described worldwide. This gene is expressed in various tissues, including the gastrointestinal tract, heart, kidney, and liver, among others [10]. Descriptions of the clinical characteristics of patients carrying new mutations are important since they may improve our understanding of multiorgan diseases and adipose tissue physiology, and this understanding may enable us to speculate about genotype-phenotype associations.

In this study, we reported two unrelated CGL1 patients with a novel frameshift mutation in AGPAT2, NM_006412:p.Leu124Serfs"26.

\section{Methods}

Clinical features and laboratory and molecular data from two Brazilian patients from the state of Ceará, Northeast Brazil (Fig. 1), were obtained by medical interview and medical records review.

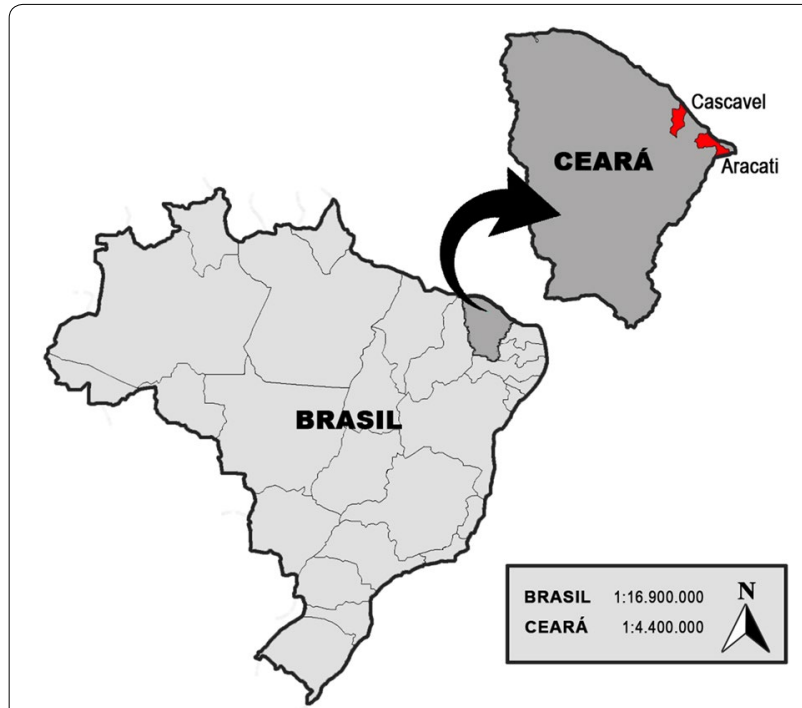

Fig. 1 CGL pa-tients' hometowns (in red) in the state of Ceará, Brazil
Blood glucose, cholesterol, and triglyceride levels were obtained after overnight fast and determined according to standard methods using automated equipment. Glycohemoglobin A1c values were determined by ion exchange high-performance liquid chromatography (HPLC), and serum insulin levels were measured by immunoassays with reagents provided by Roche Diagnostics (Basel, Switzerland). Thyroid stimulating hormone (TSH) and thyroid hormones (fT4 and T3) were measured using chemiluminescence (ADVIA Centaur ${ }^{\circledR}$ XP, Siemens). Plasma leptin levels were measured by an immunoassay using a commercial kit (DIAsource ImmunoAssays, Louvain-la-Neuve, Belgium). HOMA-IR (homeostasis model assessment) was also calculated (fasting glycaemia $(\mathrm{mmol} / \mathrm{L}) \times$ fasting insu$\operatorname{lin}(\mu \mathrm{U} / \mathrm{mL})) \div 22.5)[11]$.

Standard in-house protocols based on a salting-out method were used to extract genomic DNA from peripheral blood leucocytes [12]. The entire coding regions and intron-exon junctions of AGPAT2 and BSCL2 were amplified by polymerase chain reactions (PCR) using specific primers and were automatically sequenced; primer sequences are listed in Table 1. Amplification reactions were executed in a final volume of $25 \mu \mathrm{L}$, comprising $200 \mathrm{ng}$ genomic DNA, $0.2 \mathrm{mM}$ dNTPs, $1.5 \mathrm{mM} \mathrm{PCR}_{\mathrm{x}}$ Enhancer Solution (Invitrogen), $0.6 \mathrm{pmol}$ of each primer, $1 \times$ PCR buffer, and 1 U GoTaq ${ }^{\circledR}$ DNA polymerase (Promega, Madison, WI), and were executed for 35 cycles: denaturation at $95{ }^{\circ} \mathrm{C}$ for $30 \mathrm{~s}$, annealing at $55-62{ }^{\circ} \mathrm{C}$ for $30 \mathrm{~s}$, extension at $72{ }^{\circ} \mathrm{C}$ for $1 \mathrm{~min}$, and a final extension for $10 \mathrm{~min}$ at $72{ }^{\circ} \mathrm{C}$. The PCR products were checked on $1 \%$ agarose gel electrophoresis, purified, and automatically sequenced in an ABI PRISM ${ }^{\mathrm{TM}} 3100$ Genetic Analyzer automatic DNA sequencer (Applied Biosystems, Foster City, CA). All sequence variations were assessed on both strands and repeated in a second PCR.

Table 1 Oligonucleotides used for AGPAT2 amplification and sequencing

\begin{tabular}{ll}
\hline Primer & \\
\hline AGPAT2-1F & \\
AGPAT2-1R & $5^{\prime}$-cgcaataaggggcctgag-3' \\
AGPAT2-2F & $5^{\prime}$-ggaccccctcctgtgc-3' \\
AGPAT2-2R & $5^{\prime}$-gggactctgtccgcttca-3' \\
AGPAT2-3F & $5^{\prime}$-cagccctgtgtcctcgtc-3' \\
AGPAT2-3R & $5^{\prime}$-ggtgctcagcagctgtcttc-3' \\
AGPAT2-4F & $5^{\prime}$-tttctgccaaaaccaagtcac-3' \\
AGPAT2-4R & $5^{\prime}$-aaaacaagacccccacatcat-3' \\
AGPAT2-5F & $5^{\prime}$-gaggagtccttgtgtgtcaag-3' \\
AGPAT2-5R & $5^{\prime}$-cctcagctgtgcgtctcc-3' \\
AGPAT2-6F & $5^{\prime}$-gagtcactcattcgccacat-3' \\
AGPAT2-6R & $5^{\prime}$-ctagggagtccaggggaaga-3' \\
\hline
\end{tabular}


Mutation Taster was used to estimate the potential biological impact of the AGPAT2 mutations on the protein function. This is a web-based application that performs a battery of in silico tests on protein and DNA level to estimate the impact of a variant on the gene product. It predicts the functional consequences of amino acid substitutions as well as intronic and synonymous alterations, short insertion and deletion mutations, and variants spanning intro-exon borders. The program filter harmless mutations from the disease-causing ones by comparison with integrated databases and perform tests to determine the nature of the given variant, that comprises the amino acid substitutions, conservation of affected amino acids, potential loss of function protein domains, length of protein, conservation on DNA level, among others. The result is assessed by a probabilistic classifier which decides if the combined effect of the variant might be deleterious for the protein. The test output explains if this is a predicted pathogenical mutation with high accuracy and gives detailed information about it [13].

\section{Results}

Study subjects

Patient 1

Patient 1 was a 30 -year-old woman (Fig. 2), non-smoker, born full-term (unknown birth weight) as the third child of nonconsanguineous parents in the city of Cascavel, state of Ceará, Brazil (Fig. 1). Lipodystrophic phenotype was detected at birth and the diagnosis of CGL was given at the age of 6 months when she was hospitalized due to a respiratory infection. Hypertriglyceridemia $(223 \mathrm{mg} / \mathrm{dL})$ was also detected at that time.

She had no clinical follow-up until the age 13, when she was diagnosed with diabetes mellitus and, 2 years later, she was referred to our institution with poor glycemic control (fasting bood glucose $266 \mathrm{mg} / \mathrm{dL}$ ) and hypertriglyceridemia $(816 \mathrm{mg} / \mathrm{dL})$. At that time, her insulin dose was adjusted from 2.1 to $2.3 \mathrm{UI} / \mathrm{Kg} /$ day and she was started on metformin $1700 \mathrm{mg} /$ day, and ciprofibrate $100 \mathrm{mg} /$ day. However, she maintained poor metabolic control (A1c 12\%), with inadequate dietary adherence, and presented two episodes of pancreatitis related to hypertriglyceridemia $(2386 \mathrm{mg} / \mathrm{dL})$ at age 17 . One year later, she was diagnosed with hypertension and diabetic nephropathy (albuminuria) and was started on enalapril.

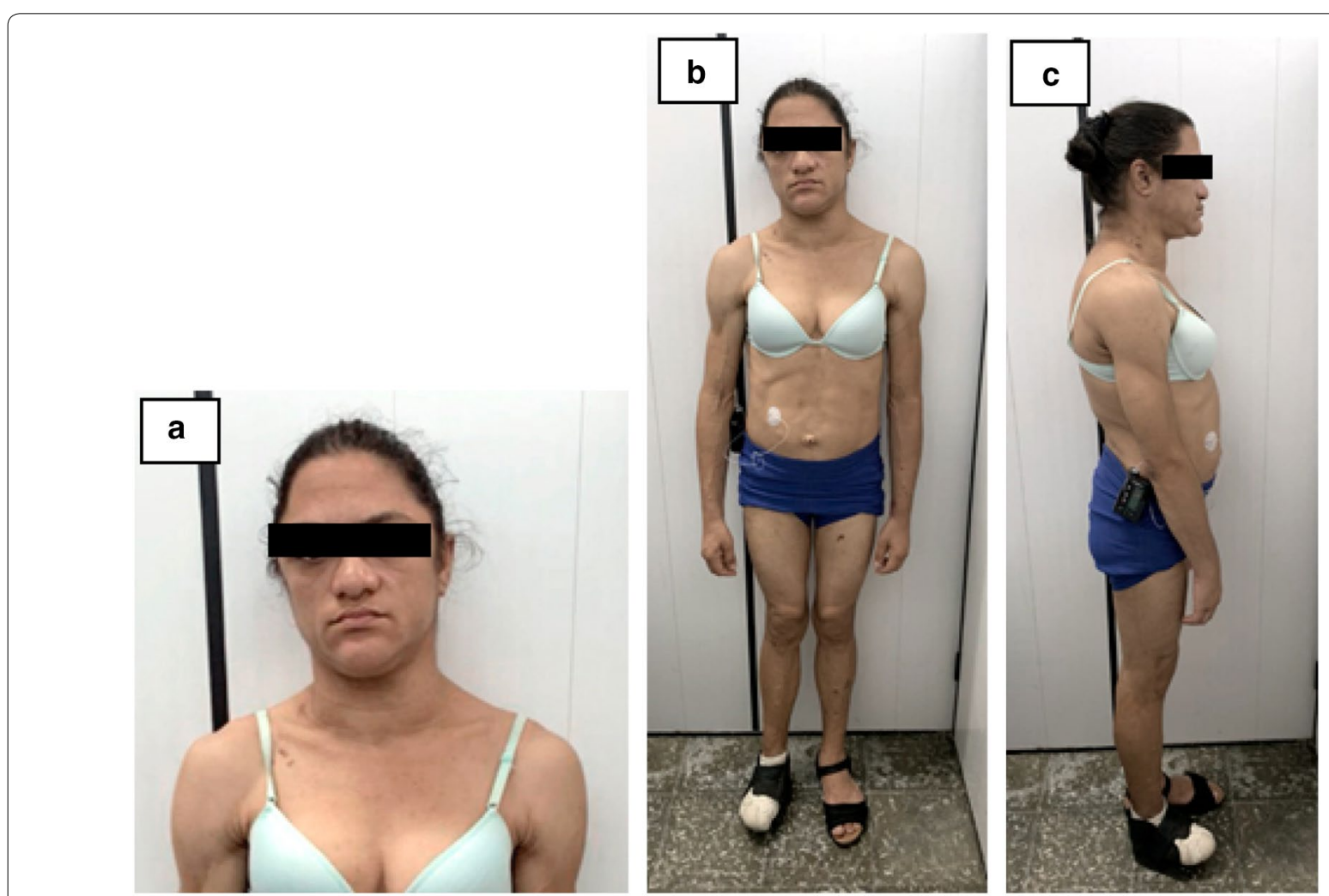

Fig. 2 Patient 1, a 30-year-old woman with type 1 congenital generalized lipodystrophy. a acromegaloid facies; $\mathbf{b}$, c generalized lack of subcutaneous fat, muscular hyperplasia, umbilical hernia, and increased abdominal volume 
At age 20, she was diagnosed with subclinical primary hyperthyroidism (TSH $0144 \mathrm{uU} / \mathrm{mL}$ and free T4 1,1 ng/ $\mathrm{dL}$ ) with a diffuse goiter, fourfold increase, with six small benign nodules on cytology (Bethesda 2 category), despite having lived in an iodine-sufficient region. She was started on methimazole.

At age 25, she presented with proliferative diabetic retinopathy and visual loss in the right eye, peripheral neuropathy, and cardiac autonomic dysfunction manifested by dizziness, resting tachycardia, and orthostatic hypotension (Table 2).

At age 29, she presented a diabetic foot ulcer that had progressed to necrotizing fasciitis and severe sepsis, leading to a forefoot amputation. During that same hospitalization, she had an acute myocardial infarction and underwent the placement of three coronary drugeluting stents due to multivessel coronary artery disease. The two-dimensional speckle-tracking echocardiography showed moderate increase of the left atrium, left ventricular concentric hypertrophy, and left ventricular dysfunction.

At age 29, her diabetic nephropathy progressed to endstage renal disease and she was started on hemodialysis.

She experienced menarche at age 17 and had two spontaneous pregnancies (at ages 22 and 26), despite a diagnosis of polycystic ovarian syndrome. Her first pregnancy resulted in a spontaneous fetal loss in the first trimester. The second pregnancy had a favorable outcome, with a healthy offspring with no CGL phenotype. No similar cases have been reported in her family.

At the time of examination, Patient 1 was $160.5 \mathrm{~cm}$ tall, weighed $58.9 \mathrm{~kg}$, and had a BMI of $22.9 \mathrm{~kg} / \mathrm{m}^{2}$. She had acromegaloid facies and a generalized lack of subcutaneous fat, with preserved fat in the palmar and plantar regions, intense acanthosis nigricans (cervical, axillary, and inguinal region), extreme muscularity, phlebomegaly, umbilical hernia, and hepatomegaly. She had no signs of intellectual impairment. Table 2 shows the main laboratory and complementary exams performed during her follow-up.

\section{Patient 2}

Patient 2 was a 12-year-old girl (Fig. 3), non-smoker, born full-term (birth weight: $3570 \mathrm{~g}$; length: $49 \mathrm{~cm}$ ) as an only child of consanguineous parents (second cousins) in the city of Aracati, state of Ceará, Brazil (Fig. 1). Lipodystrophic phenotype was detected at the age of 5 months.

At age 1, hypertriglyceridemia $(519 \mathrm{mg} / \mathrm{dL})$, acanthosis nigricans, and hepatomegaly were detected. She had thelarche at age 6.5 and pubarche at age 6.7 and, although she had not been treated, she had not yet presented with menarche. She was adherent to non-drug therapy during her follow up. At age 12, she was started on metformin due to pre-diabetes (A1c: $5.7 \%$ ). No similar cases have been reported in her family.

Table 2 Laboratory tests, abdominal ultrasound, and echocardiography of congenital generalized lipodystrophy Patients 1 and 2

\begin{tabular}{|c|c|c|c|c|}
\hline Patient & 1 & & 2 & \\
\hline Age (years old) & $15^{*}$ & $30 * *$ & $1^{*}$ & $12.2^{* *}$ \\
\hline Leptin $(\mathrm{ng} / \mathrm{mL})^{*}$ & 1.0 & - & 1.0 & - \\
\hline Total cholesterol (mg/dL) & 292 & 175 & 131 & 145 \\
\hline $\mathrm{HDL}(\mathrm{mg} / \mathrm{dL})$ & - & 25 & 26 & 18 \\
\hline HOMA-IR & NA & NA & 1.8 & 9.9 \\
\hline Glucose (fasting) (mg/dL) & 259 & 291 & 82 & 75 \\
\hline GlycohemoglobinA1c (\%) & - & 6.4 & 5.1 & 5.7 \\
\hline Triglycerides (mg/dL) & 816 & 306 & 519 & 397 \\
\hline Abdominal ultrasound & - & $\begin{array}{l}\text { Renal microlithiasis, hepato- } \\
\text { megaly, hepatic steatosis, and } \\
\text { nephromegaly }\end{array}$ & - & $\begin{array}{l}\text { Hepatomegaly, hepatic } \\
\text { steatosis, and nephro- } \\
\text { megaly }\end{array}$ \\
\hline Cardiovascular autonomic neuropathy tests ${ }^{a}$ & - & $\begin{array}{l}\text { Clinical/ } \\
\text { Advanced }\end{array}$ & - & Absent \\
\hline Conventional echocardiography & - & $\begin{array}{l}\text { increased left atrium, apical } \\
\text { hypokinesia, preserved systolic } \\
\text { function }\end{array}$ & - & Normal \\
\hline GLS by speckle-tracking echocardiography & - & $-17.9 \%^{b}$ & - & $-19.3 \%^{b}$ \\
\hline
\end{tabular}

At the first * and the last ** clinical evaluation

a Cardiovascular autonomic neuropathy tests: deep breathing test (E/I coefficient), valsalva maneuver, orthostatic test (30/15 coefficient) and orthostatic or postural hypotension test

b GLS: Global longitudinal strain, reference value (adults): -21.1 to -19.4 ; (2-9 years old): -23.9 to -22 


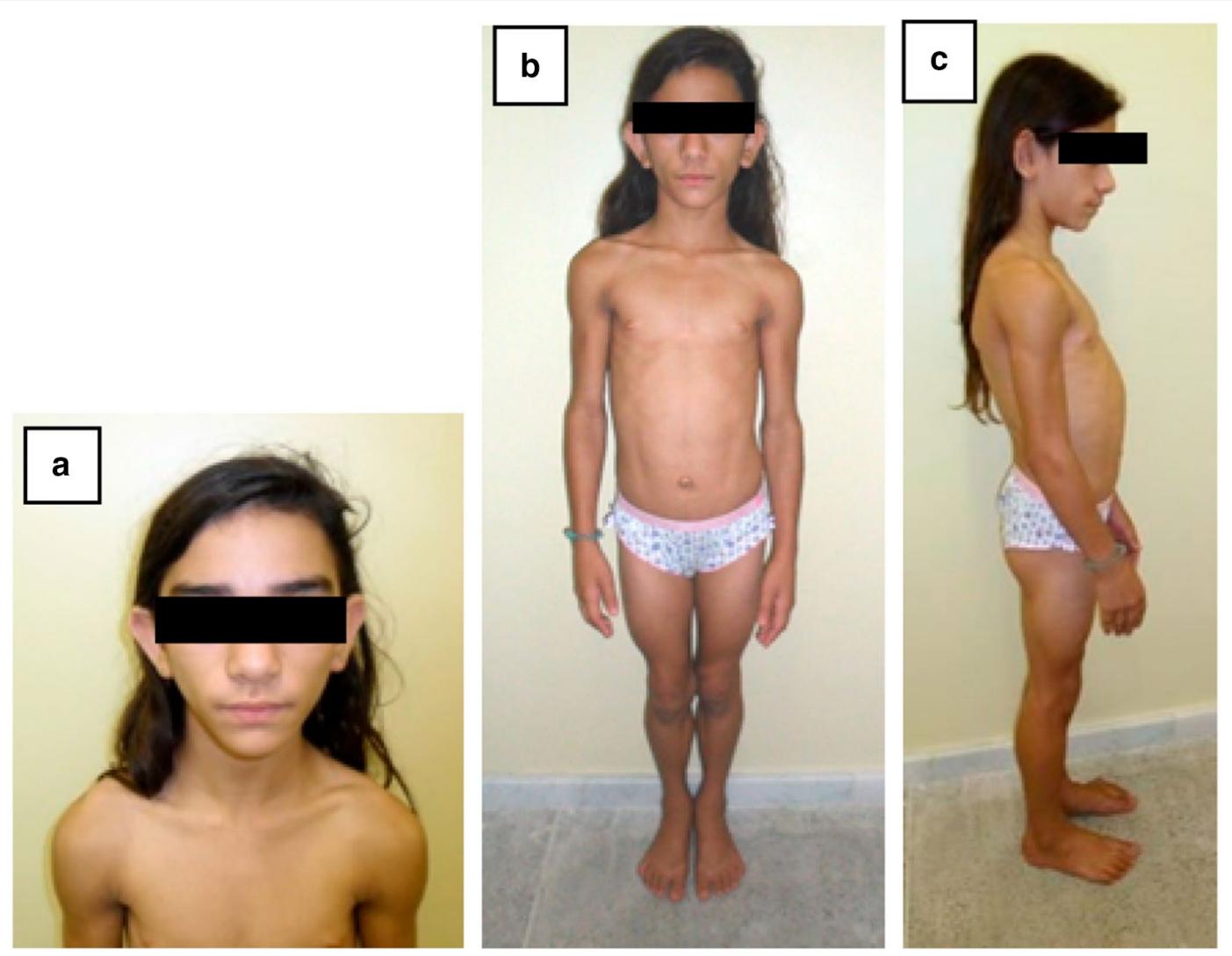

Fig. 3 Patient 2, a 12-year-old girl with type 1 congenital generalized lipodystrophy. a acromegaloid facies; b, c generalized lack of subcutaneous fat, muscular hyperplasia, umbilical hernia, and increased abdominal volume

At the time of physical examination, she was $163 \mathrm{~cm}$ tall (Z: +1.0), weighed $49.3 \mathrm{~kg}$, and her BMI was $18.6 \mathrm{~kg} /$ $\mathrm{m}^{2}$ (SD: 0.08). Her pubertal status was M4/P5 (Tanner Stage); hirsutism was present. She had acromegalic facies and a generalized lack of subcutaneous fat, with preserved fat in the palmar and plantar regions, intense acanthosis nigricans, extreme muscularity, umbilical hernia, and hepatomegaly. She had no signs of intellectual impairment. Table 2 shows the main laboratory and complementary exams performed during her follow-up.

\section{Molecular results}

Molecular analysis of Patient 1 identified two AGPAT2 mutations in heterozygosis configuring a compound heterozygous. The first mutation was a deletion of nucleotides GCTC at positions 369-372, located in exon 3 (NM_006412:c.369_372delGCTC, p.Leu124Serfs*26). The second mutation was the previously described A-for-G substitution at position -2 of the intron 4 (c.589-2A > G).

Patient 2 harbored the deletion of the GCTC nucleotides at positions $369-372$ of the transcript, located in exon 3 (NM_006412:c.369_372delGCTC) in a homozygous state (Fig. 4).

The potential impact of the p.Leu124Serfs*26 mutation on 1-AGPAT2 protein function was evaluated by the Mutation Taster tool, being considered disease causing. The probability value, i.e. the probability of prediction was 1 , meaning a "high security" of the disease causing prediction.

\section{Discussion}

In this paper, we have described in detail a novel pathogenic mutation in AGPAT2, Leu124Serfs*26; and investigated its potential impact on the clinical features of CGL in two unrelated patients.

Molecular analysis identified a deletion of 4 nucleotides at position 369-372 of the exon 3, resulting in substitution of a leucine (hydrophobic amino acid) to serine (neutral polar amino acid) at codon 124 and a stop codon at the 26th position from the first amino acid changed, generating a truncated protein. Some in silico tools can be used to assess possible effects of an amino-acid substitution on the function and structure of human proteins, using straightforward physical and comparative 


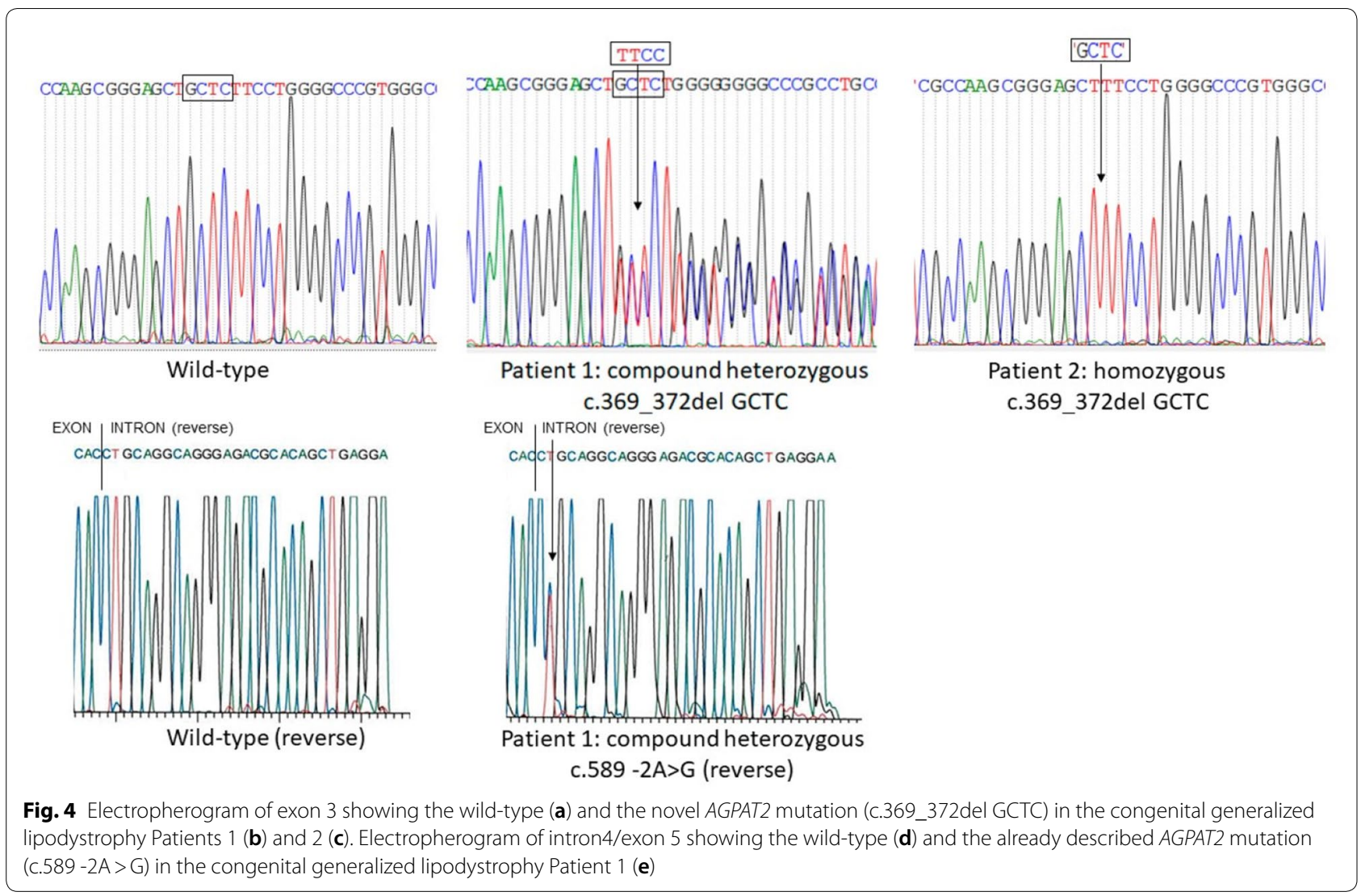

considerations. Leu124Serfs*26 was analyzed using Mutation Taster tool and was predicted to be pathogenic, with a high probability value. It generated a truncated protein, probably causing a drastic alteration in the protein function, which is related to the CGL1 phenotype. A previous article on cardiovascular autonomic neuropathy in our sample of CGL patients mentioned this mutation in a supplementary table. However, it did not describe the clinical characteristics of these two patients [14].

The 1-AGPAT2 is a membrane bound protein located in the endoplasmic reticulum that consists of 278 amino acids with two highly conserved motifs among the other acyltransferases; $\mathrm{NHX}_{4} \mathrm{D}$ (amino acids 97-103) and EGTR (amino acids 172-175) are both crucial for enzymatic activity $[15,16]$. The NHX4D motif is cytoplasmically oriented whereas the EGTR motif is in the lumen of the endoplasmic reticulum. To be catalytically active, both motifs should come together on the same side of the membrane [10]. The Leu124Serfs $* 26$ mutation affects the second highly conserved motif, making a complete loss of enzymatic activity predictable.

Patient 1 also carried the c.589-2A $>$ G mutation in her AGPAT2 gene, characterizing a compound heterozygous with the c.369_372delGCTC, p.Leu124Serfs*26 mutation. Thirty-seven different mutations in AGPAT2 have been described worldwide related to congenital generalized lipodystrophy [17]. Globally, the most common mutation is the c.589$2 \mathrm{~A}>\mathrm{G}$ (rs116807569). In Brazil, the predominant CGL mutations are c.589-2A $>$ G, c.317-588del, c.646A $>$ T, and $c .570 \mathrm{C}>\mathrm{A}$ in the AGPAT2 gene [17-19]. Our historical relationship with Portugal and Africa during colonization and the previous description of the c.589$2 \mathrm{~A}>\mathrm{G}$ mutation in these locations suggest a founder effect (Fig. 5) [17, 20].

Both patients manifested early metabolic complications. Patient 1 had two episodes of pancreatitis related to hypertriglyceridemia and a diagnosis of diabetes at age 13 with poor glycemic control. Patient 2 also presented with hypertriglyceridemia (in the first year of life) and had pre-diabetes detected at age 12, despite having adherence to the non-drug therapy. According to the literature, about half of CGL patients have the onset of diabetes at puberty [7]. Agarwal et al. [20] reported $18 / 38$ CGL1 patients with diabetes, with the mean age of diabetes onset at age $16.8 \pm 10.1$, and 8/16 CGL2 patients with diabetes who had an earlier diabetes onset at the mean age of $9.5 \pm 3.1$ years. In a large Brazilian series, where approximately 70\% had CGL2, the mean age of diabetes onset was $15.8 \pm 7.1$ years old [19]. 


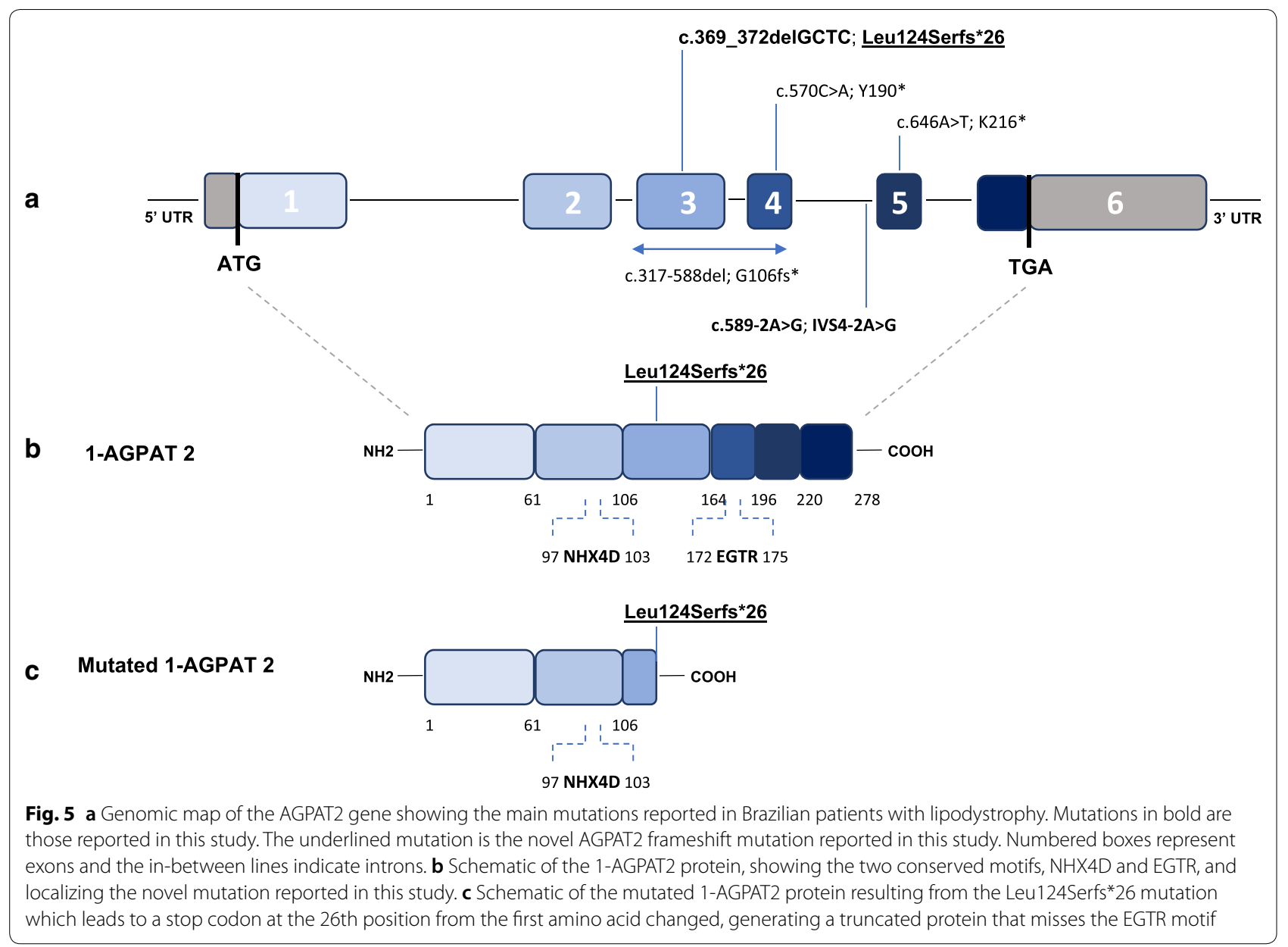

Patient 1 had severe and early micro- and macrovascular complications detected approximately 5 years after the diabetes diagnosis, as well as end-stage renal disease, autonomic cardiovascular neuropathy and acute myocardial infarction at age 29. Ponte et al. [14] observed early commitment of cardiovascular autonomic modulation in 10/20 young CGL patients, detected through abnormalities in cardiovascular autonomic neuropathy tests.

High rates of coronary artery disease (CAD) would be expected to be more common in CGL patients due to the severity of metabolic complications. Otherwise, the CAD complications are not usually described in patients with CGL [19, 21-23]. Few cases of CAD have been reported [21]. Agarwal et al. [20] reported that 13\% of 38 CGL1 patients had cardiomegaly but did not observe any cases of CAD. Lupsa et al. [22] observed 1/19 CGL1 patients with coronary artery disease; the one was a woman (unknown mutation) who underwent myocardial revascularization at age 45 . In a Turkish series, 3/16 CGL1 patients had CAD at age 30,62, and 62, respectively, carrying c.662-2A > C (IVS5-2A >C), c.202C > T (p.R68*), and c.685G > T (p.E229*) AGPAT2 mutations. The younger one had also renal failure [23].

Patient 2 had already presented abnormalities in the global longitudinal strain, evaluated by speckle-tracking echocardiography (2D-STE), at an incredibly young age. The 2D-STE is a promising echocardiography technique that plays an important role in early detection of cardiac dysfunction. It is more sensitive than ejection fraction to detect subclinical left ventricular systolic dysfunction, because evaluates percentage of myocardial fiber deformation throughout the cardiac cycle [24]. A recent study described that $15 / 22(68.2 \%)$ young patients with CGL had left ventricular systolic dysfunction detected by 2D-STE, even with normal conventional echocardiography [25].

Peripheral arterial disease is a common macrovascular complication in diabetic patients but is rarely described in CGL patients. In a Turkish series, lower limb amputations were described in $2 / 16$ patients at ages 25 and 30, carrying c.646A $>\mathrm{T}\left(\mathrm{p} . \mathrm{K} 216^{*}\right)$ and c.662-2A $>\mathrm{C}$ (IVS5-2A > C) AGPAT2 mutations, respectively [23]. Our 
Patient 1 presented with a foot ulcer, evolving with forefoot amputation and characterizing a severe and precocious vascular complication.

Patient 1 presented with asymptomatic renal lithiasis. The most common renal finding in CGL is nephromegaly, but renal lithiasis was also described in a 2-month-old Persian child who carried a nonsense mutation in exon 6 of AGPAT2 (c.685G > T, p.Glu229*) [26]. Obesity, diabetes, and metabolic syndrome have been associated with renal lithiasis $[27,28]$. Insulin resistance inhibits proximal tubule ammoniagenesis, causing an acidic milieu that increases the risk of uric acid calculi, but this has been related to cases with high body-mass indexes [29]. Another reason for the presence of urolithiasis could be the high intake of animal proteins and polyphagia in obese people, which is also observed in CGL patients due to leptin deficiency [30].

The thyroid can be affected by IR through the anabolic action of high insulin levels. The clinical manifestations are larger thyroid volume and the genesis of nodules [31-33]. Patient 1 had a diffuse goiter along with cold nodules. There are few descriptions of thyroid abnormalities in patients with CGL. Akinci et al. [23] described a female 62-year-old patient with toxic multinodular goiter who was a carrier of the c.202C > T (p.R68*) mutation.

Patient 1 presented with late menarche, and Patient 2 exhibited precocious puberty (thelarche, pubarche, increased growth velocity), but, even untreated, had still not experienced menarche. Although patients with CGL have accelerated growth [7] and precocious thelarche and/or pubarche (unpublished data), primary or secondary amenorrhea are common [34, 35]. High levels of androgens related to insulin resistance may contribute to the precocious pubarche $[5,35]$.

Pregnancy is rare in CGL, and only two patients have been reported with a favorable outcome [36]. Loss of the pulsatile secretion of gonadotropins and hyperandrogenism may impair ovulation and pregnancy, and poorly controlled diabetes in CGL patients gives rise to high-risk pregnancies [7]. However, our Patient 1 had one pregnancy with a favorable outcome and a healthy offspring with no CGL phenotype, despite Patient 1's poor glycemic control.

This study had some limitations. Genetic information of the patients' ancestors was not available, and the possibility of a founder effect was not evaluated. Additionally, it is not possible to be sure of a genotype-phenotype correlation based only on two case reports.

\section{Conclusion}

We described two unrelated patients with type 1 congenital generalized lipodystrophy born in the same Brazilian region presenting with the Leu124Serfs*26, a novel frameshift mutation in AGPAT2. Their clinical manifestations were characterized by early and severe cardiovascular disease, which suggests a possible association between this mutation and a more aggressive phenotype. However, additional studies are needed, as a cell culture of a homozygous patient, to better stablish the role of the new discovered mutation.

\begin{abstract}
Abbreviations
A1c: Glycohemoglobin A1c; AGPAT2: 1-Acylglycerol-3-phosphate O-acyltransferase 2 gene; 1-AGPAT2: 1-Acylglycerol-3-phosphate O-acyltransferase 2 protein; BRAZLIPO: Brazilian Group for the Study of Inherited and Acquired Lipodystrophies; BSCL2: Bernardinelli-Seip congenital lipodystrophy type 2 gene; BSCL2: Bernardinelli-Seip congenital lipodystrophy type 2 protein; CAD: Coronary artery disease; CAVIN1: Caveolae associate protein 1; CAV-1: CAVEOLIN 1 gene; CGL: Congenital generalized lipodystrophy; CGL1: Congenital generalized lipodystrophy type 1; CGL2: Congenital generalized lipodystrophy type 2; DNA: Deoxyribonucleic acid; DM: Diabetes mellitus; fT4: Free tiroxine; GLS: Global longitudinal strain; HOMA-IR: Homeostasis model assessment of insulin resistance; HPLC: High-performance liquid chromatography; IR: Insulin resistance; M4/P5: Tanner stage; OMIM: Online Mendelian inheritance in man; PCR: Polymerase chain reaction; PPARY: Peroxisome proliferator-activated receptor gamma; SD: Standard deviation; TSH: Thyroid stimulating hormone; T3: Triiodothyronine.
\end{abstract}

\section{Acknowledgements}

The authors would like to thank Lívia Batista for assistance during the laboratory analyses (Clinical Research Unit, University Hospital, Federal University of (eará).

\section{Authors' contributions}

RMMJ contributed to the conception and design of the study; analysis and interpretation of the data; and drafting and revising the manuscript. GECPL contributed to the conception and design of the study; analysis and interpretation of the data; and drafting and revising the manuscript. VOF, AMP, CMMP, and LVM contributed to the acquisition of data and revising the manuscript. CBD contributed to the interpretation of the data and drafting and revising the manuscript. DPP contributed to the acquisition of data and revising the manuscript. MEAM and MOMF contributed to the interpretation of the data and revising the manuscript. All the authors have given final approval of the version to be published and agreed to be accountable for all aspects of the work, including its accuracy and integrity. All authors read and approved the final manuscript.

\section{Funding}

This work was supported by Grant 481129/2009-0 from the National Council for Scientific and Technological Development (CNPq), Brasília, Brazil.

\section{Availability of data and materials}

The datasets generated during and/or analyzed during the current study are available from the corresponding author upon reasonable request.

\section{Ethics approval and consent to participate}

Written informed consent was obtained from all subject patients and their families. The study protocols for these trials were approved by the University Hospital Walter Cantídio Ethics Committee, Fortaleza, Ceará, Brazil (LEC approval number 2627842, in accordance with the Declaration of Helsinki.

\section{Consent for publication}

All patients have provided authorization for publication of case report and photos.

\section{Competing interests}

The authors declare that they have no competing interests. 


\begin{abstract}
Author details
${ }^{1}$ Brazilian Group for the Study of Inherited and Acquired Lipodystrophies (BRAZLIPO), Faculdade de Medicina, Universidade Federal do Ceará, Rua Professor Costa Mendes, 1608, Rodolfo Teófilo, Fortaleza, Ceará 60416200, Brazil. ${ }^{2}$ Drug Research and Development Center_NPDM, Universidade Federal do Ceará, Fortaleza, Brazil.
\end{abstract}

Received: 5 November 2019 Accepted: 1 April 2020

Published online: 06 April 2020

\section{References}

1. Van Maldergem L, Magre J, Khallouf TE, Gedde-Dahl T, Delepine M, Trygstad O, et al. Genotype-phenotype relationships in Berardinelli-Seip congenital lipodystrophy. J Med Genet. 2002;39(10):722-33.

2. Gomes KB, Fernandes AP, Ferreira ACS, Pardini H, Garg A, Magré J, et al. Mutations in the seipin and AGPAT2 genes clustering in consanguineous families with Berardinelli-Seip congenital lipodystrophy from two separate geographical regions of Brazil. J Clin Endocrinol Metab. 2004;89(1):357-61.

3. Pardini VC, Victória IMN, Rocha SMV, Andrade DG, Rocha AM, Pieroni FB, et al. Leptin levels, $\beta$-cell function, and insulin sensitivity in families with congenital and acquired generalized lipoatropic diabetes. J Clin Endocrinol Metab. 1998;83(2):503-8.

4. Agarwal AK, Arioglu E, de Almeida S, Akkoc N, Taylor SI, Bowcock AM, et al. AGPAT2 is mutated in congenital generalized lipodystrophy linked to chromosome 9q34. Nat Genet. 2002;31(1):21.

5. Garg A. Lipodystrophies: genetic and acquired body fat disorders. J Clin Endocrinol Metab. 2011;96(11):3313-25.

6. Shindou H, Hishikawa D, Harayama T, Yuki K, Shimizu T. Recent progress on acyl CoA: lysophospholipid acyltransferase research. J Lipid Res. 2009;50(Supplement):S46-51.

7. Patni N, Garg A. Congenital generalized lipodystrophies-new insights into metabolic dysfunction. Nat Publ Gr. 2015. https://doi.org/10.1038/ nrendo.2015.123

8. Gale SE, Frolov A, Han X, Bickel PE, Cao L, Bowcock A, et al. A regulatory role for 1-acylglycerol-3-phosphate-O-acyltransferase 2 in adipocyte differentiation. J Biol Chem. 2006:281(16):11082-9.

9. Cortés VA, Curtis DE, Sukumaran S, Shao X, Parameswara V, Rashid S, et al. Molecular mechanisms of hepatic steatosis and insulin resistance in the AGPAT2-deficient mouse model of congenital generalized lipodystrophy. Cell Metab. 2009;9(2):165-76.

10. Agarwal AK. Lysophospholipid acyltransferases: 1-acylglycerol-3-phosphate O-acyltransferases. From discovery to disease. Curr Opin Lipidol. 2012;23(4):290-302.

11. Matthews DR, Hosker JP, Rudenski AS, Naylor BA, Treacher DF, Turner RC. Homeostasis model assessment: insulin resistance and $\beta$-cell function from fasting plasma glucose and insulin concentrations in man. Diabetologia. 1985;28(7):412-9.

12. Miller SA, Dykes DD, Polesky $H$. A simple salting out procedure for extracting DNA from human nucleated cells. Nucleic Acids Res. 1988;16(3):1215.

13. Schwarz JM, Cooper DN, Schuelke M, Seelow D. MutationTaster2: mutation prediction for the deep-sequencing age. Nat Methods. 2014;11(4):361-2.

14. Ponte CMM, Fernandes VO, Gurgel MHC, Vasconcelos ITGF, Karbage LBAS, Liberato CBR, et al. Early commitment of cardiovascular autonomic modulation in Brazilian patients with congenital generalized lipodystrophy. BMC Cardiovasc Disord. 2018;18(1):6.

15. Leung DW. The structure and functions of human lysophosphatidic acid acyltransferases. Front Biosci. 2001;6(1):D944-53.

16. Li D, Yu L, Wu H, Shan Y, Guo J, Dang Y, et al. Cloning and identification of the human LPAAT-zeta gene, a novel member of the lysophosphatidic acid acyltransferase family. J Hum Genet. 2003;48(8):438.

17. Sarmento ASC, Ferreira LC, de Lima JG, de Azevedo Medeiros LB, Cunha PTB, Agnez-Lima LF, et al. The worldwide mutational landscape of Berardinelli-Seip congenital lipodystrophy. Mutat Res Mutat Res. 2019;781:30-52.

18. Fu M, Kazlauskaite R, Paiva Baracho MF, Nascimento Santos MGD, Brandão-Neto J, Villares S, et al. Mutations in Gng3lg and AGPAT2 in
Berardinelli-Seip congenital lipodystrophy and Brunzell syndrome: phenotype variability suggests important modifier effects. J Clin Endocrinol Metab. 2004:89(6):2916-22.

19. Lima JG, Nobrega LHC, De Lima NN, Goretti M, Baracho MFP, Maria S, et al Clinical and laboratory data of a large series of patients with congenital generalized lipodystrophy. Diabetol Metab Syndr. 2016;8:1-7.

20. Agarwal AK, Simha V, Oral EA, Moran SA, Gorden P, O'rahilly S, et al. Phenotypic and genetic heterogeneity in congenital generalized lipodystrophy. J Clin Endocrinol Metab. 2003;88(10):4840-7.

21. Hussain I, Patni N, Garg A. Lipodystrophies, dyslipidaemias and atherosclerotic cardiovascular disease. Pathology. 2018;51(2):202-12.

22. Lupsa BC, Sachdev V, Lungu AO, Rosing DR, Gorden P. Cardiomyopathy in congenital and acquired generalized lipodystrophy: a clinical assessment. Medicine. 2010;89(4):245.

23. Akinci B, Onay H, Demir T, Ozen S, Kayserili H, Akinci G, et al. Natural history of congenital generalized lipodystrophy: a nationwide study from Turkey. J Clin Endocrinol Metab. 2016;101(7):2759-67.

24. Amundsen $\mathrm{BH}$, Helle-Valle T, Edvardsen T, Torp H, Crosby J, Lyseggen E, et al. Noninvasive myocardial strain measurement by speckle tracking echocardiography: validation against sonomicrometry and tagged magnetic resonance imaging. J Am Coll Cardiol. 2006;47(4):789-93.

25. Liberato CBR, Olegario NBC, Fernandes VO, Montenegro APDR, Lima GECP, Batista LAA, Martins LV, Penaforte-Saboia JG, Liberato ILRB, Lope LF, d'Alva CB, Furtado FLB, Lima RLM, Nóbreg LHC, Lima JG, MonteneroJunior $\mathrm{R}$. Early left ventricular systolic dysfunction detected by two-dimensional speckle-tracking echocardiography in young patients with congenital generalized lipodystrophy. Diabetes, Metab Syndr Obes Targets Ther. 2020;13:107-15.

26. Haghighi A, Razzaghy-Azar M, Talea A, Sadeghian M, Ellard S, Haghighi A. Identification of a novel nonsense mutation and a missense substitution in the AGPAT2 gene causing congenital generalized lipodystrophy type 1. Eur J Med Genet. 2012;55(11):620-4

27. Taylor EN, Curhan GC. Body size and 24-hour urine composition. Am J Kidney Dis. 2006;48(6):905-15.

28. Pak CYC, Sakhaee K, Moe O, Preminger GM, Poindexter JR, Peterson RD, et al. Biochemical profile of stone-forming patients with diabetes mellitus. Urology. 2003;61(3):523-7.

29. Abate N, Chandalia M, Cabo-Chan AV Jr, Moe OW, Sakhaee K. The metabolic syndrome and uric acid nephrolithiasis: novel features of renal manifestation of insulin resistance. Kidney Int. 2004;65(2):386-92.

30. Daudon M, Lacour $B$, Jungers P. Influence of body size on urinary stone composition in men and women. Urol Res. 2006;34(3):193.

31. Duran AO, Anil C, Gursoy A, Inanc M, Bozkurt O, Tutuncu NB. Thyroid volume in patients with glucose metabolism disorders. 2014;58(8):824-7.

32. Rezzonico J, Rezzonico M, Pusiol E. Introducing the thyroid gland as another victim of the insulin resistance syndrome. Thyroid. 2008;18(4):461-4

33. Ayturk S, Gursoy A, Kut A, Anil C, Nar A, Tutuncu NB. Metabolic syndrome and its components are associated with increased thyroid volume and nodule prevalence in a mild-to-moderate iodine-deficient area. Eur J Endocrinol. 2009;161:599-605.

34. Upreti V, Dhull P, Patnaik SK, Kumar KVSH. An unusual cause of delayed puberty: Berardinelli-Seip syndrome. J Pediatr Endocrinol Metab. 2012;25(11-12):1157-60.

35. Musso C, Cochran E, Javor E, Young J, DePaoli AM, Gorden P. The longterm effect of recombinant methionyl human leptin therapy on hyperandrogenism and menstrual function in female and pituitary function in male and female hypoleptinemic lipodystrophic patients. Metabolism. 2005;54(2):255-63.

36. Maguire M, Lungu A, Gorden P, Cochran E, Stratton P. Pregnancy in a woman with congenital generalized lipodystrophy: leptin's vital role in reproduction. Obstet Gynecol. 2012;119(2 Pt 2):452.

\section{Publisher's Note}

Springer Nature remains neutral with regard to jurisdictional claims in published maps and institutional affiliations. 